\title{
Application of physiologically based modelling and transcriptomics to probe the systems toxicology of aldicarb for Caenorhabditis elegans (Maupas 1900)
}

\author{
Jodie F. Wren · Peter Kille • David J. Spurgeon • \\ Suresh Swain · Stephen R. Sturzenbaum • \\ Tjalling Jager
}

Accepted: 28 December 2010/Published online: 21 January 2011

(C) The Author(s) 2011. This article is published with open access at Springerlink.com

\begin{abstract}
The toxicity of aldicarb on movement, life cycle, population growth rate and resource allocation, and the gene expression changes underpinning these effects, were investigated for Caenorhabditis elegans. A clear effect of aldicarb on nematode movement was found suggesting that this pesticide acts as a neurotoxicant. Aldicarb also had an effect on life cycle traits including low concentration life-span extension; high concentration brood size reduction and a high concentration extension of time to first egg. All life-cycle and growth data were integrated into a biology-based model (DEBtox) to characterise
\end{abstract}

Electronic supplementary material The online version of this article (doi:10.1007/s10646-010-0591-z) contains supplementary material, which is available to authorized users.

J. F. Wren · P. Kille

School of Biosciences, Cardiff University, Park Place, Cardiff CF10 3TL, UK

J. F. Wren · D. J. Spurgeon

Centre for Ecology and Hydrology, Monks Wood, Abbots

Ripton, Huntingdon, Cambridgeshire PE27 2LS, UK

D. J. Spurgeon $(\square)$

Centre for Ecology and Hydrology, Maclean Building,

Benson Lane, Crowmarsh Gifford, Wallingford,

Oxfordshire OX10 8BB, UK

e-mail:dasp@ceh.ac.uk

S. Swain · S. R. Sturzenbaum

Pharmaceutical Science Division, King's College London,

150 Stamford Street, London SE1 9NH, UK

T. Jager

Department of Theoretical Biology, Vrije Universiteit

Amsterdam, De Boelelaan 1085, 1081 HV Amsterdam,

The Netherlands aldicarb effects on life-history traits, resource allocation and population growth rate within a single modelling framework. The DEBtox fits described concentration dependent effects on individual traits and population growth rate and indicated that the most probable mechanism of action of the pesticide was an increase in energy demands for somatic and reproductive tissue maintenance. Transcriptomic profiling indicated that aldicarb was associated with changes in amino acid metabolism, DNA structure, fatty acid metabolism and cytochrome P450 mediated xenobiotic metabolism. The changes in the amino acid and fatty acid pathways suggest an effect of aldicarb on protein integrity; while effects on DNA suggests that aldicarb influence DNA morphology or replication. Both these effects have the potential to incur increased costs for structural maintenance of macromolecules. These effects, coupled to the effect on biotransformation enzymes also seen, represent the materialisation of the maintenance costs indicated by DEBtox modelling.

Keywords Resource allocation - Reproduction - Lifespan - DEBtox - Cytochrome P450 - Protein metabolism

\section{Introduction}

A major aim of ecotoxicology is to discover the mechanisms through which toxicants affect the physiology of individuals and to link these observations to effects on populations. Since toxicants typically affect several lifehistory traits simultaneously, the use of full life-cycle toxicity tests can provide invaluable information on the sub-lethal effects of chemicals (Kammenga et al. 1996). Further life-cycle tests can also be used to predict the population growth rate consequences of exposure, and to 
produce useful ecological risk assessment metrics (e.g. population growth rate) that are indicative of long-term effects (Calow et al. 1997).

While life-history analysis can provide useful insights into the population effects of toxicants, detailed molecular analyses are needed to understand the mechanisms governing such changes. The measurement of toxicant induced impacts on gene and protein expression and metabolite concentrations offer the chance to understand how effects on life history are mediated at the molecular level. The use of toxicogenomics in ecotoxicology is rapidly evolving and increasing (Williams et al. 2003; Heckmann et al. 2006; Soetaert et al. 2007; Svendsen et al. 2008; Owen et al. 2008; Bundy et al. 2008). To date, however, only a few of these studies have attempted to link gene/protein expression responses to life history changes elicited by toxicant exposure (Connon et al. 2008; Swain et al. 2010).

An obstacle to integration of the life-history and toxicogenomic approaches within an ecotoxicological context is that each operates at different levels of biological organisation, even though they are, of course, inextricably linked. One approach that can help to conjoin these analyses is the use of biology-based models. These simulation based methods can provide insight into how toxicological effects on physiological processes are linked to the resulting impacts on life-history traits. One of the most well known biologically-based models is DEBtox (Alda Alvarez et al. 2005; Jager et al. 2006). This model framework is based on dynamic energy budget (DEB) theory (Kooijman 2001). It integrates data for multiple toxicity endpoints measured over time to simulate the responses of life-history traits and population growth to chemical exposure. One use of DEBtox analysis is to establish plausible indications of the metabolic process most likely to be affected by the toxicant (AKA the physiological mode of action). This assessment is done in DEBtox by sequentially fitting separate models, each describing a mode of action using life-history data. The best fitting model then represents the most probable mechanism (Alda Alvarez et al. 2006). Examples of modes of action applicable to the DEBtox format are: (i) decrease of assimilation-in which there is a toxic effect on feeding rate or energy assimilation from food; (ii) increase in maintenance costs-where a toxic effect increases energy costs for maintaining somatic and reproductive tissue; (iii) increase in growth costs-where the toxicant increases the costs for making new tissues; (iv) increase in costs for reproduction-where energetic costs of toxicity relates to the production of offspring; and (v) hazard to embryowhere the toxicant directly reduces embryo survival. These modes of action each produce distinctive phenotypes in relation to patterns of survival, growth and reproduction over time (Jager et al. 2004), and have been associated to different patterns of transcription in studies with the nematode Caenorhabditis elegans exposure to non-specific chemicals (Swain et al. 2010).

Here we used $C$. elegans to study the toxicology of a putative specifically acting chemical, namely aldicarb. By exploiting a combination of life-cycle toxicity testing and DEBtox modelling it was possible to first define the toxicity at the whole organism level, and then to relate these major changes to effects within the transcriptome. This combined approach sought to generate a hypothesis concerning the physiological (resource allocation based) mode of action of aldicarb using DEBtox and then investigate the validity of this hypothesis through targeted gene expression analysis. Aldicarb was selected for the study because it has a well characterised major specific mode of toxicity for target and non-target organisms, including nematodes. The pesticide is predicted predominantly to exert toxicity by inhibiting acetylcholinesterase (AChE). This causes an accumulation of the neurotransmitter at the synapse resulting in an over stimulation of nerve cells and classic twitching and convulsive behaviour (Opperman and Chang 1992). While acetylcholinesterase inhibition is thought to be the main mechanism for aldicarb toxicity, it is also known that aldicarb has other targets (Cid and Matos 1984, 1987). These neurological and other toxicodynamic effects of aldicarb can each instigate a cascade of further effects that impact on behavioural and life-cycle traits.

\section{Materials and methods}

Nematode culturing and exposures

All tests were performed on C. elegans strain N2 (wild type) obtained from the Caenorhabditis Genetics Center (University of Minnesota, MN, USA). Nematodes were cultured at $15^{\circ} \mathrm{C}$ on NGM agar plates $(1.7 \%$ bacto agar, $0.025 \%$ bacto peptone, $50 \mathrm{mM} \mathrm{NaCl}, 0.005 \%$ cholesterol, $1 \mathrm{mM} \mathrm{CaCl}_{2}, 1 \mathrm{mM} \mathrm{MgSO}_{4}$, and $25 \mathrm{mM} \mathrm{KH}_{2} \mathrm{PO}_{4}$ ) seeded with Escherichia coli strain OP50 as a food source (Brenner 1974). The exposure temperature was purposefully chosen to be at the lower end of the standard range for two specific reasons: firstly, egg counting, encompassing all doses, could be performed simultaneously over an extended period (thus maximizing technical replication) and secondly, this temperature was deemed to reflect more realistically a temperature that is common to temperate soils. Aldicarb (Sigma, UK) was dosed as required by dissolving in sterile bidistilled water and added to the NGM agar at concentrations of $1,4,8,12$, and $16 \mathrm{mg} / \mathrm{l}$ at $50^{\circ} \mathrm{C}$. The concentrations were selected to cover an exposure range from "no effect" to a concentration above the $\mathrm{EC}_{50}$ for brood size (as established from a previous preliminary study). The high concentration used reflects an 
apparent insensitivity of $C$. elegans to aldicarb in this system that could be associated with the binding of aldicarb to the complex macromolecules present in NGM agar. Control NGM agar was prepared without the addition of aldicarb.

\section{Life-cycle toxicity testing}

The life-cycle test was performed with age synchronised nematodes. These were obtained by transferring gravid adults to standard NGM plates for $4 \mathrm{~h}$, removing the adults and then allowing the eggs to hatch and develop to maturity. A second synchronisation was then performed in the same way, but this time worms were introduced to control and aldicarb dosed plates. The worms that hatched during this second synchronisation were measured for size every 4-5 h until they reached the L4 stage. Thereafter, 24 nematodes per dose were transferred to individual agar wells in 12 multi-well plates for assessment of egg laying. Every $12 \mathrm{~h}$ throughout the reproductive period, surviving adults were transferred to a fresh well of appropriately dosed agar and any eggs laid counted.

The life-history traits measured over the full life-cycle were: life-span (survival), time to reproduction, length of the reproductive period, reproduction over time, and growth over time. Life-span was assessed by observing nematodes following mechanical stimulation to confirm that both movement and pharyngeal pumping had ceased. Time to first egg was determined to within $12 \mathrm{~h}$ by searching for the presence of eggs on plates after transfer. Length of the reproductive period was taken as the time between first and last egg laying. Reproduction (brood size) was determined by counting the number of offspring (hatched eggs) in each well $24 \mathrm{~h}$ after transfer. This meant that the reproduction measurements captured effects on both egg laying and egg viability, although these effects could not be separated. Growth was assessed by photography and digital size measurement at $12 \mathrm{~h}$ intervals.

\section{Movement assays}

Movement was assessed in a separate experiment for each aldicarb concentration used in the full life-cycle test. Nematodes were exposed on agar from hatching and tested at the young adult stage. Movement traits measured were (i) distance moved on agar, and (ii) number of tail thrashes in liquid medium. Total distance moved was determined over a $30 \mathrm{~s}$ period for $20(0-8 \mathrm{mg} / \mathrm{l})$ or $10(12,16 \mathrm{mg} / \mathrm{l})$ exposed worms using digital photography and ImagePro Express (Media Cybernetics, Marlow, UK). Tail thrashing (single thrash $=$ tail moving from one side to the other and back) was monitored in $100 \mu$ of appropriately dosed M9 buffer with the number of thrashes per 30 s recorded for 10
$(0-8 \mathrm{mg} / \mathrm{l})$ or $5(12,16 \mathrm{mg} / \mathrm{l})$ young adult worms previously grown on control or dosed NGM agar.

Microarray fabrication

Caenorhabditis elegans microarrays were printed in house using the $C$. elegans oligonucleotide set version 1.1 $\left(\right.$ Operon $\left.^{\mathrm{TM}}\right)$. Oligonucleotides in this set have been designed to the most $3^{\prime}$ region and are $70 \mathrm{bp}$ in length (70 mers). The set comprised 19,873 oligonucleotides. These were printed in $3 \times$ SSC buffer using a Perkin Elmer SpotArray 72 onto UltraGAPS ${ }^{\mathrm{TM}}$ slides (Corning, Barry, UK) at a concentration of $15 \mu \mathrm{M}$. Landmarks were printed in the top left hand corner of each sub-array for orientation and the Lucidea universal scorecard (Amersham, Buckinghamshire, UK) also printed at a concentration of $25 \mu \mathrm{M}$. Oligonucleotides were immobilised by baking at $80^{\circ} \mathrm{C}$ for $2 \mathrm{~h}$ and UV cross linked in a UV Stratalinker ${ }^{\mathrm{TM}} 2400$ bench top transilluminator (Stratagene Ltd., USA).

Reporter annotation was performed using the MegaBlast algorithm to identify the best match to the oligonucleotide sequences with cDNAs associated with release WS140 version of the $C$. elegans genome (Sanger Center release July 2005), the Refseq cDNA data set (NCBI release August 2005) and all deposited mRNAs/ESTs present in GenBank (August 2005) allowing a maximum of a 2 basepair mismatch. Physical location and gene ontology was assigned from genome release WS140 associated to the matching WormBase gene identifier. Human homologues were identified using the Ensembl orthologue prediction tables (Sanger Center release July 2005).

\section{Design of aldicarb exposures for microarray analysis}

The microarray experiment followed a reference design, with the reference sample constituting an equal proportion of control and aldicarb exposed nematode RNA, labelled with Cy3 which was then hybridised with each Cy5 labelled sample from an experiment which comprised a binary comparison between controls worms and $16 \mathrm{mg} / \mathrm{l}$ exposed worms. This concentration was selected as it induced greatest impacts on life-cycle traits and while this did not allow all phenotypic effects to be addressed, it did allow an assessment that focussed on the major toxicological effects. Five biological replicate samples were compared to the reference RNA for each of the two treatments. Each replicate consisted of a batch of approximately 10,000 stage synchronised worms obtained by two rounds of sodium hypochlorite bleaching. The replicate worms were grown on NGM separate agar plates exposed to 0 and $16 \mathrm{mg} / \mathrm{l}$ aldicarb under the same conditions as was used in the life-cycle test conducted with individuals. Each separate plate of worm corresponded to one of the five 
biological replicates per treatment. At the young adult stage for each replicate (when eggs were first spotted in one of the individually monitored worms for a given treatment), exposed worms were washed off NGM plates in M9 buffer, centrifuged and the supernatant removed to leave a worm pellet. Samples for microarray analysis were, thus, lifestage rather that temporally synchronised.

\section{Nucleic acid extraction}

Per replicate, $100 \mu \mathrm{l}$ of worm sample was homogenized in TRI $^{\circledR}$ reagent (Sigma Chemical, Poole, UK) by vortexing for $3 \mathrm{~min}$ in the presence of an equal amount of glass beads (Sigma). Total RNA was extracted using the protocol of Chomczynski and Sacchi (1987). Total RNA was purified using an RNeasy kit (Qiagen, UK), quantified by spectrophotometry (ultraspec 2100pro UV/visible spectrophotometer, Amersham Biosciences), and integrity assessed by the visualization of ethidium bromide staining of ribosomal bands on a $1 \%$ agarose gel.

\section{Microarray hybridization}

The Lucidea Universal Scorecard test spike mRNAs (Amersham Biosciences) were added to each $15 \mu \mathrm{g}$ test RNA and universal reference RNA. Test RNA was labelled with $\mathrm{Cy} 5$ and the universal reference with $\mathrm{Cy} 3$. The labelled test and reference RNA samples were reverse transcribed to cDNA with 150 pmol oligo dT, $0.2 \mathrm{mM}$ aminoallyl dUTP (aadUTP), $1 \mathrm{mM}$ dATP, $1 \mathrm{mM}$ dCTP, $1 \mathrm{mM}$ dGTP, $0.4 \mathrm{mM}$ dTTP, and 500 units MMuLV (Moloney Murine Leukaemia Virus) reverse transcriptase in $4 \mu \mathrm{l}$ of $5 \times$ RT buffer (ABgene, Surrey, UK). Fluorescent dyes $\mathrm{Cy} 3$ and $\mathrm{Cy} 5$ were indirectly coupled to the amino group on the aminoallyl dUTPs.

Labelled cDNA was purified to remove unincorporated dye using the CyScribe ${ }^{\text {TM }}$ GFX Purification Kit (Amersham Biosciences) and cDNA quantity and incorporation of dyes assessed by absorption measurement. The microarray slides were pre-treated in blocking solution $(1 \%$ BSA, $5 \times$ SSC and $0.1 \%$ SDS) at $42^{\circ} \mathrm{C}$ for $30 \mathrm{~min}$. Slides were then washed in $0.2 \mu \mathrm{M}$ filter-sterilised water followed by isopropanol and then dried under compressed air. A 20 pmol sample of each Cy3 and Cy5 labelled cDNA was combined and denatured at $95^{\circ} \mathrm{C}$ for $3 \mathrm{~min}$ and immediately applied onto the blocked slide in a $2 \times$ hybridisation buffer $(50 \%$ formamide, $10 \times \mathrm{SSC}, 0.2 \%$ SDS) in a total volume of $40 \mu \mathrm{l}$. A second slide was applied to the array surface and hybridised at $42^{\circ} \mathrm{C}$ for $18 \mathrm{~h}$. After hybridisation, slides were separated in $1 \times \mathrm{SSC}, 0.1 \%$ SDS buffer and washed for $10 \mathrm{~min}$ in the same buffer at $55^{\circ} \mathrm{C}$. After two further washes in $0.1 \times \mathrm{SSC}, 0.1 \%$ SDS buffer at $55^{\circ} \mathrm{C}$ and two rinses, one in $1 \times \mathrm{SSC}$ buffer and one in $0.1 \times \mathrm{SSC}$, the slides were dried and imaged using a ScanArray ${ }^{\mathrm{TM}}$ Express HT microarray scanner (Perkin-Elmer) at $543 \mathrm{~nm}$ for $\mathrm{Cy} 3$ and $633 \mathrm{~nm}$ for Cy5.

\section{Statistical analysis}

One way analysis of variance (ANOVA) was used to investigate treatment effects on individual life-history traits and nematode movement. Movement parameters, life-span, brood size and length of adult period accorded closely to normality assumptions. Time to first egg, however, showed significant deviation from normality. Common transformations such as logarithm and square root did not result in normalised data so this parameter was also analysed by ANOVA as untransformed values, and also analysed using the non-parametric Kruskal-Wallis test. When differences were found by the ANOVA, a Tukey's multiple comparison test was used to determine whether there were significant differences (at the 5\% level) between treatments. The $\mathrm{EC}_{50}$ (including $95 \%$ confidence intervals) for reproduction was calculated for total brood size using a logistic model.

The available life-history data was used to parameterise the DEBtox model in order to assess the responses of individual traits, effect on population growth rate and the energetic basis of the observed effects. DEBtox is a biologically-based model initially developed by Kooijman and Bedaux (1996) that is based on the DEB theory. Adaptations for use with $C$. elegans include: (i) simultaneous modelling of all traits (Jager et al. 2004), (ii) different shape of growth curve due to feeding limitations in juveniles (Jager et al. 2005), (iii) a maximum total number of eggs for hermaphroditic C. elegans due to sperm limitation (Jager et al. 2005), (iv) including senescence effects on survival (Alda Alvarez et al. 2005) and, (v) allowing the body size at the start of reproduction to decrease with stress (Alda Alvarez et al. 2005).

The modified DEBtox model was used to analyse aldicarb effects on life-cycle traits and to discern physiological mode of action and a range of other physiologically relevant parameters. All model fits were conducted using maximum likelihood estimation in Matlab ${ }^{\circledR}$ Version 7.3 (Release 2006b). The effects on survival and reproduction were integrated into an estimate for population growth $(r)$ using the continuous version of the Euler-Lotka equation (see Jager et al. 2004). Estimates were based on the derived DEBtox model fits as well as on the raw data themselves (making them continuous over time using piecewise cubic interpolation). Assessment of effects on $r$ provides a means through which the long-term multigenerational effects of aldicarb on populations can be assessed.

Acquired microarray images were quantified using ImaGene $^{\mathrm{TM}}$ (Biodiscovery Inc., CA, USA) using the default flagging and segmentation settings. Spot fluorescence, 
background fluorescence and other contaminants on the slide were separated. Analysis of control plots of ScoreCard hybridization were performed using the raw image analysis data derived from each array. Hybridisations showing nonlinear responses, or where the detection limit was above the 10 pg Lucidea ScoreCard calibrator, were removed from the analysis.

Normalization and statistical analysis was initially performed in GeneSpring GX 7.3 (Agilent Technologies, Palo Alto, USA). Array data passing quality standard checks were processed by background subtraction, $\log _{2}$ transformed and a $\mathrm{Cy} 3 / \mathrm{Cy} 5$ ratio obtained. Lowess normalisation of the entire dataset was conducted using per gene and per chip normalisation. The processed data were visualised using a box plot to identify any abnormal samples. As sample C5 displayed an aberrant profile, this sample was removed from all further statistical analysis giving four replicates only for the control treatment. The remaining nine replicates (four control, five $16 \mathrm{mg} / \mathrm{l}$ exposed) were used for statistical analysis.

The normalised data was first filtered to eliminate spots only present in one channel, spots not flagged as good in at least four samples and spots where the reference (Cy3) signal intensity was less than 100 pixels. Data was then filtered to generate two separate gene list based on fold change and statistical significance. The first gene list was generated by first filtering to identify genes displaying 1.4 fold differential up or down expression in aldicarb exposed worms and then further filtering to identify genes significantly changing in expression at the $5 \%$ level using $t$-test, with false discovery rate multiple testing correction (Benjamini and Hochberg 1995). This first (shorter) list was used in the analysis to highlight individual differentially expressed genes and for functional analysis using the Gene Ontology (GO) annotation browser in GeneSpring which uses Benjamini-Yekutelli multiple sample correction to allow for the dependency with parent and daughter terms with the focus only on terms represented by ten or more genes. The second gene list generated comprised transcripts that displayed a greater than 2 fold change in expression (up or down) in aldicarb exposed worms. This longer list was utilised for the principal component analysis (PCA) and for annotation enrichment analysis using the Database for Annotation, Visualization and Integrated Discovery (David) 2.1 to identify KEGG (Kyoto Encyclopaedia of Genes and Genomes) pathways and annotation terms overrepresented within this gene list. This web based resource provides a set of functional annotation tools for identification of biological meaning within differentially regulated gene lists. This dual approach gave a more holistic view of aldicarb effects on transcription. All microarray data collected was fully MIAME compliant and has been submitted to GEO.

\section{Results}

\section{Movement}

Aldicarb significantly reduced thrashing rate $(\mathrm{F}=43.23$, $p<0.001$ ) (Fig. 1a) and distance moved on agar ( $\mathrm{F}=44.53, p<0.001)$ (Fig. 1b) with both parameters significantly reduced at concentrations of $4 \mathrm{mg} / \mathrm{l}$ and above (Tukey's post-hoc test, $p<0.05$ ). At $16 \mathrm{mg} / \mathrm{l}$, movement on agar was greatly inhibited and tail thrashing reduced by 90\% (Fig. 1a). Such effects are consistent with neurotoxin exposure supporting the notion that aldicarb effects nematodes through acetylcholinesterase inhibition (Opperman and Chang 1991).

\section{Life-history}

Mean lifespan for control nematodes was 16 days. Exposure to aldicarb significantly affected lifespan (Fig. 2a) $(\mathrm{F}=9.37, p<0.001)$, resulting in significant extension (37\%) at $4 \mathrm{mg} / \mathrm{l}$ (Tukey's post-hoc test, $p<0.001$ ), although not at lower and higher concentrations. Exposure to aldicarb also significantly affected time to first egg whether assessed by ANOVA $(\mathrm{F}=15.83, p<0.001)$ or
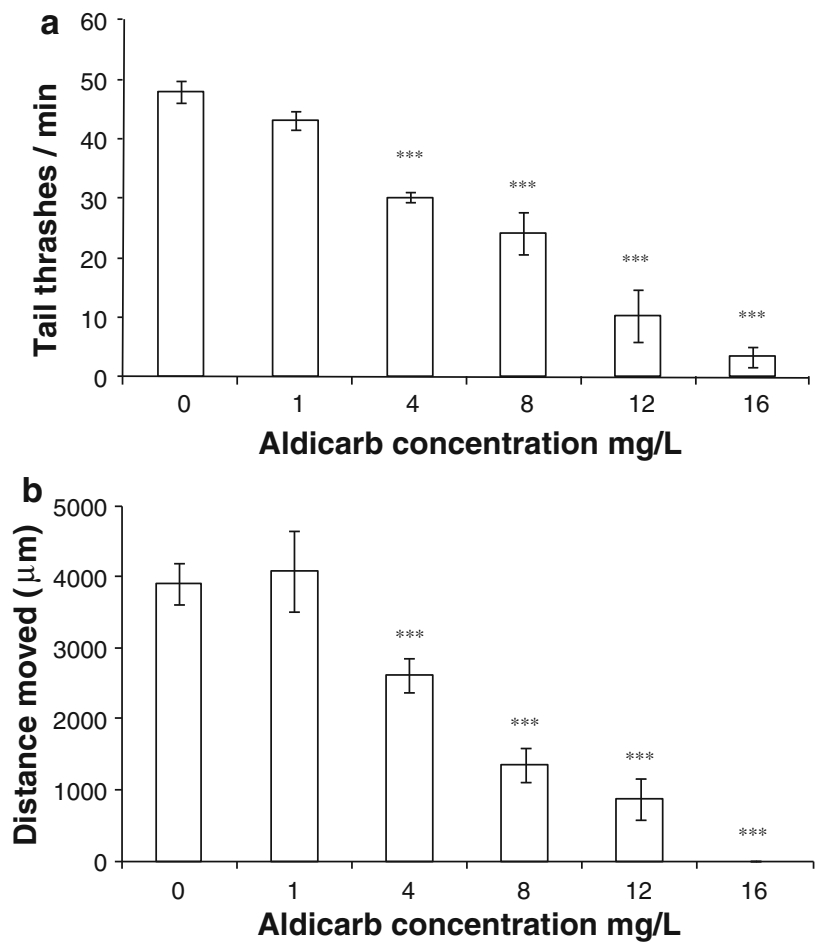

Fig. 1 Movement of L4 stage nematodes under control and aldicarb exposure a movement in liquid medium measured as the mean number of tail thrashes in $30 \mathrm{~s} \mathbf{b}$ movement on agar measured as the distance moved by the nematode in $30 \mathrm{~s}$, error bars are standard error of mean, asterisks indicate significant differences from controls at $* * * p<0.001$ 

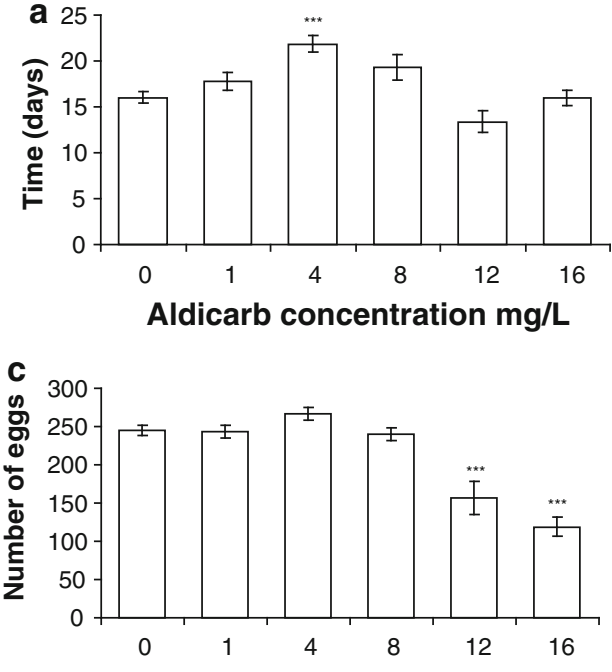

Aldicarb concentration $\mathrm{mg} / \mathrm{L}$

Fig. 2 Effects on a mean life-span $\mathbf{b}$ mean time to first egg $\mathbf{c}$ total brood size and $\mathbf{d}$ mean length of the reproductive period for $C$. elegans exposed individually over the full life-cycle to control or five

the non-parametric Kruskal-Wallis test $(\mathrm{H}=43.1, p<$ 0.001) (Fig. 2b). There was an increase at $16 \mathrm{mg} / \mathrm{l} \mathrm{com-}$ pared to all treatments (Tukey's post-hoc test, $p<0.001$ ) and also an increase at $1 \mathrm{mg} / \mathrm{l}$ compared to controls (Tukey's post-hoc test, $p<0.05$ ).

Worms exposed to all aldicarb concentrations produced viable offspring even at the highest concentration indicating that although movement was greatly impaired, sufficient muscle activity remained (as indicated by the reduced but not absent tail thrashing) to allow egg production. Mean brood size in the control worm was 245 eggs/worm. Aldicarb significantly affected reproductive output $(\mathrm{F}=26.99$, $p<0.001$ ), with brood size significantly reduced at both 12 and $16 \mathrm{mg} / \mathrm{l}$ (Tukey's post-hoc test, $p<0.001$ ) (Fig. 2c). The $\mathrm{EC}_{50}( \pm 95 \%$ confidence intervals) for reproduction was $14.9(13.6-16.2) \mathrm{mg} / \mathrm{l}$ aldicarb. Length of the reproductive period was also significantly affected by aldicarb ( $\mathrm{F}=18.26, p<0.001$ ), being decreased at $1 \mathrm{mg} / \mathrm{l}$ (Tukey's post-hoc test, $p<0.001$ ) and increased at $16 \mathrm{mg} / \mathrm{l}$ (Tukey's post-hoc test, $p<0.001$ ) (Fig. 2d).

Nematode growth was measured from L1 stage $(26 \mathrm{~h}$ after synchronisation) for 7 days until all worms were adult. Results indicated that final body size was significantly reduced compared to controls at all concentrations $(p<0.05)$.

All survival, reproduction and growth data was used to fit a series of DEBtox models for aldicarb effects from which to assign the most plausible energy-budget-based mechanism of toxicity. The models used differed in the metabolic process assumed to be targeted by the compound and although in reality not mutually exclusive, each represents a physiologically distinct effect on resource
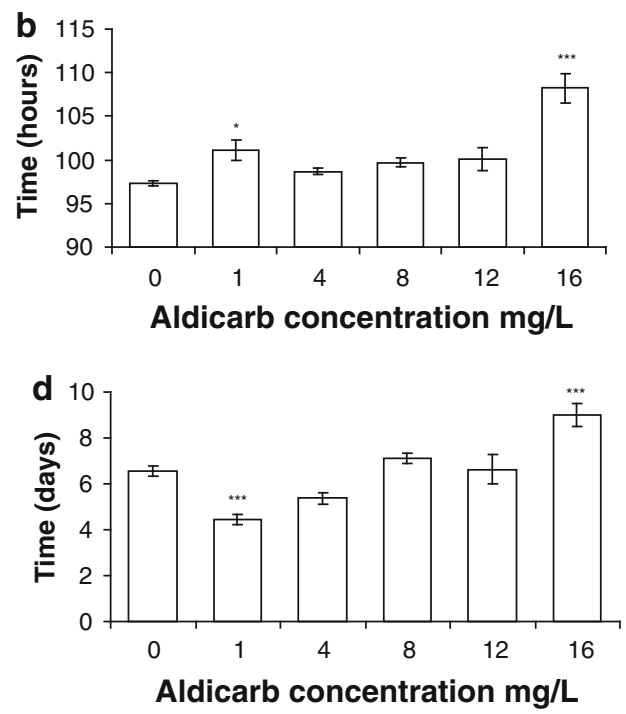

concentrations of aldicarb, error bars are standard error of mean, asterisks indicate significant differences from controls at: $* p<0.05$, $* * * p<0.001$

allocation with the best fitting model being the most plausible dominant mechanism. Parameters estimated from each DEBtox fit included no-effect concentration (NEC) for both survival and for maintenance (note these are not to be confused with the NOEC, since the NEC is a time independent model parameter) and a range of further physiological, ageing and toxicological parameters (Table 1).

Fitting of models for a range of plausible modes of action indicated that a model accounting for an increase in maintenance costs committed to the protection and repair of somatic tissues best accounts for the observed effects of aldicarb on body size (Fig. 3a) and cumulative reproduction (Fig. 3b). A decrease in assimilation of energy from food could also plausibly explain observed toxicity, although there was a lower likelihood for this model than for maintenance. For fraction surviving (Fig. 3c), the model fit for maintenance is less convincing as the extended lifespan at low concentrations could not be fully captured. This increase though possibly reflects a link between maintenance under stress and protection of somatic tissue against aging related damage and so is not incompatible with a maintenance effect. We did not though attempt to model this change in longevity by modification of the DEBtox models since this was not the focus of the study. Consequently only survival data for up to 15 days of exposure was used for the final model fitting. Within the model describing the effects of increased maintenance costs, the NEC for survival was $3.45 \mathrm{mg} / \mathrm{l}$ and the NEC for effects on growth and reproduction $1.99 \mathrm{mg} / \mathrm{l}$. Thus sublethal effects were predicted to occur at lower concentrations than mortality by a factor of 1.7 . 
Table 1 Parameters derived from DEBtox model fits of time series life-history trait data for Caenorhabditis elegans exposed to a control and a series of aldicarb concentrations in nematode growth medium agar

\begin{tabular}{|c|c|}
\hline & Aldicarb \\
\hline \multicolumn{2}{|l|}{ Physiological parameters } \\
\hline Von Bertalanffy growth rate $\left(\right.$ days $\left.^{-1}\right)$ & 0.377 \\
\hline Initial length $(\mu \mathrm{m})$ & 25.1 \\
\hline Length at which ingestion is half of maximum $(\mu \mathrm{m})$ & 38.5 \\
\hline Length at start of reproduction $(\mu \mathrm{m})$ & 87.2 \\
\hline Maximum length $(\mu \mathrm{m})$ & 152 \\
\hline Maximum reproduction rate (eggs/days) & 269 \\
\hline \multicolumn{2}{|l|}{ Ageing parameters } \\
\hline Maximum total number of eggs & 247 \\
\hline Damage killing rate $\left(\right.$ days $\left.^{-1}\right)$ & $8.5710^{-4}$ \\
\hline Damage amplification $\left(\right.$ days $\left.^{-1}\right)$ & 0.351 \\
\hline \multicolumn{2}{|l|}{ Toxicological parameters } \\
\hline Mode of action & Maintenance costs \\
\hline Elimination rate $\left(\right.$ days $\left.^{-1}\right)$ & 0.233 \\
\hline NEC for survival (mg/l) & 3.45 \\
\hline Killing rate (1/mg/days) & $6.10 \times 10^{-3}$ \\
\hline NEC for effects on maintenance $(\mathrm{mg} / \mathrm{l})$ & 1.99 \\
\hline Tolerance concentration $(\mathrm{mg} / \mathrm{l})$ & 9.20 \\
\hline Decrease length at puberty due to chemical stress $[-]$ & 0.715 \\
\hline Decrease total eggs due to chemical stress $[-]$ & 2.46 \\
\hline
\end{tabular}
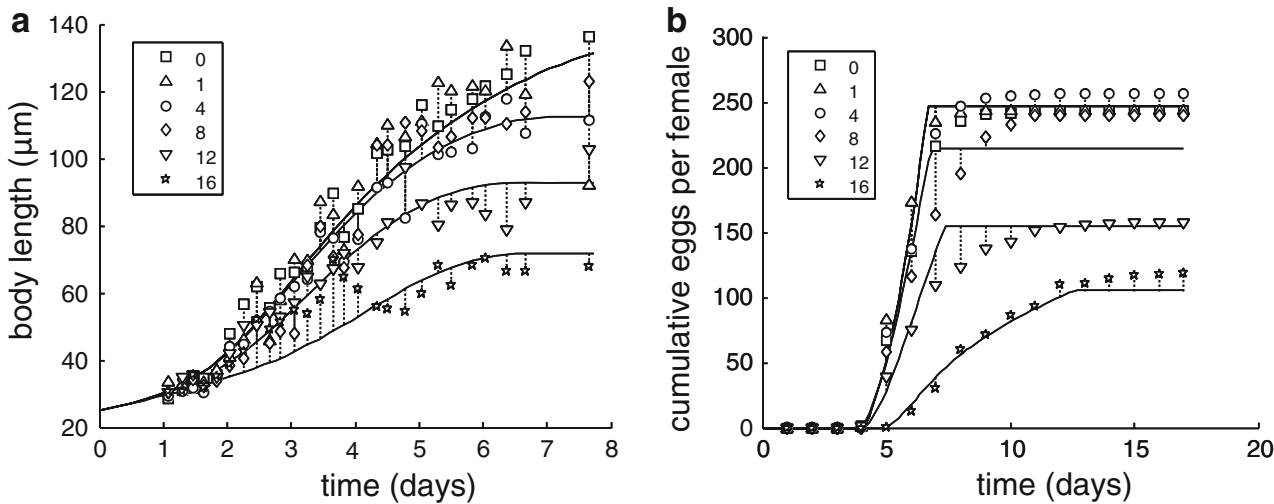

Fig. 3 DEBtox model fits of life-history consequences of aldicarb exposure assuming toxic effects through a physiological effect of increasing resource allocation to maintenance of somatic tissue: symbols show observed data $(\mathrm{mg} / \mathrm{l})$ and lines the model fits for $\mathbf{a}$ body length $\mathbf{b}$ cumulative reproduction (brood size) c fraction surviving over time d estimated population growth rate estimated using the continuous Euler-Lotka equation with symbols representing predictions for test concentrations and the line splines calculated from the estimated population growth rate values

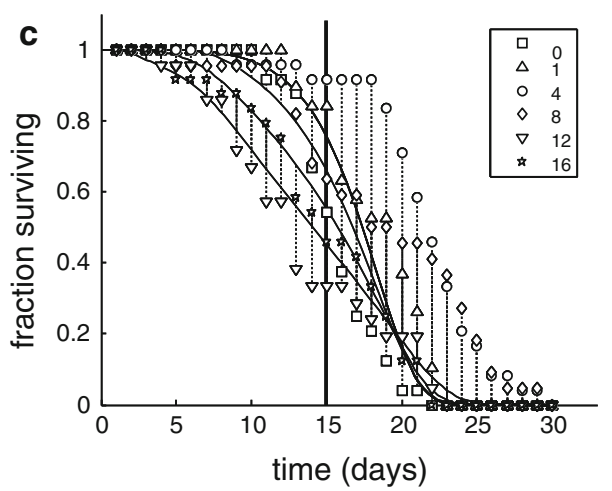

Effects on survival and reproduction were integrated into a projection of population growth rate $(r)$ as a function of aldicarb exposure (Fig. 3d). The projection is shown as a continuous function because the DEBtox model allows effects to be calculated for any concentration, using the parameter estimated in Table 1. Projections based on the 
data directly (without model fitting) are shown as dots. These projections indicate a decrease in $r$ at the two highest exposure concentrations indicating a population-level effect due to toxicity.

\section{Gene expression}

Microarray data quality was initially assessed by examining the quantifications of the synthetic mRNA controls (Lucidea scorecards) included in the experiment to confirm linearity of signal intensity. Box plots of normalised data were also used to ensure appropriate distribution of signal intensity indicative of a successful hybridisation. Four controls (C1-4) and five $16 \mathrm{mg} / \mathrm{l}$ exposed (A1-5) samples were appropriately hybridised.

Data filtering based on a cut-off of 1.4 fold change in expression revealed 8,282 aldicarb responsive genes (4,960 up-regulated, 3,322 down-regulated). Statistical analysis of this set of fold change filtered genes using $T$-test with Benjamini and Hochberg false discovery correction identified 380 significant up-regulated genes and 282 significant downregulated genes (see Supplementary Table 1). A number of these significant genes were functionally associated with key life-history traits. Twenty-six genes associated with reproduction were up-regulated and six down-regulated. These genes were predominantly linked to "housekeeping" functions such as maintenance of DNA integrity, protein synthesis and protein trafficking. For growth effects, the gene hoe-1 (E04A4.4) which is required for normal rapid growth in C. elegans (Kamath et al. 2003; Smith and Levitan 2004), was up-regulated almost 9-fold in aldicarb exposed nematodes. Six genes linked to the ontology term "determination of adult lifespan", including two 7-transmembrane receptors and a GTP-ase activating protein were also significantly induced with down-regulated genes associated with this term predominately involved in receptor activity, including 7-transmembrane olfactory receptors, 7-transmembrane receptors, G-protein coupled receptors, a GABA receptor and nuclear hormone receptors.

Gene Ontology (GO) annotation analysis in GeneSpring GX was used to identify biochemical pathways affected by aldicarb. Only $40 \%$ of the gene list was annotated (167 out of the 380 up-regulated genes, and 95 of the 282 downregulated genes), thus the pathways highlighted can only claim to represent a snap-shot of all potential responses of C. elegans to aldicarb. Nevertheless, biological processes were identified that were statistically over-represented in the up-regulated gene list. These related to chromosome organization and biogenesis (GO:7001), protein metabolism (GO:19538), macromolecule catabolism (GO:9057), protein ubiquitination (GO:16567), ubiquitin cycle (GO:6512), osmoregulation (GO:18987), and ageing/determination of adult lifespan (GO:7568, GO:8340) (Table 2). The effects on DNA and chromosome structures were notable $(p<0.001)$, with a number of genes including multiple histones and genes involved in heterochromatin assembly being upregulated up to four fold in response to aldicarb exposure (Fig. 4). No GO terms represented by more than ten genes were over-represented in the significantly downregulated gene list.

Data filtering using a 2 fold change cut off resulted in a list of 4,496 up-regulated and 627 down-regulated genes. A PCA conducted using this list of 2 fold or greater changing genes indicated that control and $16 \mathrm{mg} / \mathrm{l}$ aldicarb exposed samples could be separated from each other along the first principal component (Fig. 5). This confirms that worms maintained on aldicarb show transcriptional remodelling as a result of exposure. The list of 2 fold differentially regulated genes was imported into David 2.1 to identify overrepresented KEGG pathways and annotation terms. The David pathway analysis identified that the metabolism of trichloroethylene pathway was significantly enriched due to the differential expression of alcohol dehydrogenase (1.1.1.1), UDP-glucuronosyltransferase (2.4.1.17) and Cytochrome P450 (1.14.14.1) (Supplementary Fig. 1). The latter gene has also been implicated in the metabolism of the organic molecules naphthalene, 1-nitronapthalene, bromobenzene and benzo(a)pyrene (KEGG-pathway: HSA00980). This suggests a possible role of these enzymes in the biotransformation of aldicarb. Another pathway highly represented among $>2$ fold changing genes was fatty acid metabolism (Supplementary Fig. 2). The effects on this pathway denote a possible shift of substrate resources used for metabolism potentially associated with the changes in protein turnover as a result of aldicarb exposure.

\section{Discussion}

Aldicarb or 2-methyl-2-(methylthio)propanal $O$-( $N$-methylcarbamoyl)oxime is a carbamate insecticide used in commercial and domestic horticulture. Aldicarb has a halflife of 1 day to several months in water and is known to be sensitive to both microbial and photo-degradation (Howard 1991). This means that over the time course of any test, the concentration of aldicarb in the exposure medium will vary, although in this experiment this effect was limited by the daily transfer of exposed adult worms to freshly dosed plates during the reproductive period. Exposure of worms to aldicarb through both the aqueous and dietary route is feasible, although for soft bodied organisms such as nematodes which, in this exposure system, live in close contact with the agar surface it might be expected that the dermal route (i.e. passive diffusion via the cuticle) will dominate.

On uptake, aldicarb is characterised as a fast-acting cholinesterase inhibitor (Cremlyn 1991), that causes 
Table 2 Overrepresented biological processes gene ontology categories in the significantly up-regulated gene list derived from the comparison of transcription profiles of Caenorhabditis elegans exposed to 0 and $16 \mathrm{mg} / \mathrm{l}$ aldicarb

\begin{tabular}{|c|c|c|c|c|}
\hline GO term & Category & $\begin{array}{l}\text { Genes } \\
\text { in category }\end{array}$ & $\begin{array}{l}\% \text { Of genes } \\
\text { in category in list }\end{array}$ & $\mathrm{p}$-Value \\
\hline GO:16265 & Death & 118 & 5.1 & 0.026 \\
\hline GO: 16567 & Protein ubiquitination & 174 & 4.6 & 0.019 \\
\hline GO:18987 & Osmoregulation & 184 & 4.3 & 0.026 \\
\hline GO:19538: & Protein metabolism & 1284 & 2.9 & 0.007 \\
\hline GO:30163 & Protein catabolism & 32 & 9.4 & 0.023 \\
\hline GO:31497 & Chromatin assembly & 75 & 6.7 & 0.014 \\
\hline GO:42592 & Homeostasis & 197 & 4.1 & 0.037 \\
\hline GO:43170 & Macromolecule metabolism & 1571 & 2.9 & 0.003 \\
\hline GO:43283 & Biopolymer metabolism & 1042 & 3.3 & 0.001 \\
\hline GO:43285 & Biopolymer catabolism & 39 & 7.7 & 0.039 \\
\hline GO:44238 & Primary metabolism & 2438 & 2.4 & 0.038 \\
\hline GO:44260 & Cellular macromolecule metabolism & 1298 & 2.8 & 0.014 \\
\hline GO:44267 & Cellular protein metabolism & 1274 & 2.8 & 0.011 \\
\hline GO:50874 & Organismal physiological process & 265 & 3.8 & 0.033 \\
\hline GO:51276 & Chromosome organization and biogenesis & 109 & 7.3 & 0.001 \\
\hline GO:6259 & DNA metabolism & 200 & 4.5 & 0.015 \\
\hline GO:6323 & DNA packaging & 102 & 7.8 & $<0.001$ \\
\hline GO:6325 & Establishment and/or maintenance of chromatin architecture & 102 & 7.8 & $<0.001$ \\
\hline GO:6333 & Chromatin assembly or disassembly & 98 & 8.2 & $<0.001$ \\
\hline GO:6334 & Nucleosome assembly & 71 & 7 & 0.012 \\
\hline GO:6461 & Protein complex assembly & 83 & 6 & 0.022 \\
\hline GO:6512 & Ubiquitin cycle & 185 & 4.3 & 0.027 \\
\hline GO:6996 & Organelle organization and biogenesis & 227 & 4 & 0.032 \\
\hline GO:7001 & Chromosome organization and biogenesis (sensu Eukaryota) & 108 & 7.4 & 0.001 \\
\hline GO:7568 & Aging & 96 & 6.3 & 0.011 \\
\hline GO:8150 & Biological_process & 6414 & 2.1 & 0.028 \\
\hline GO:8340 & Determination of adult life span & 96 & 6.3 & 0.011 \\
\hline GO:9057 & Macromolecule catabolism & 60 & 6.7 & 0.028 \\
\hline
\end{tabular}

accumulation of acetylcholine at the synaptic cleft, thereby resulting in continued nerve excitation, tremors and ultimately behavioural toxicity, life-history changes and death (Walker 2008). Aldicarb has previously been shown to initiate paralysis in C. elegans at a concentration of $0.1 \mathrm{mM}(19 \mathrm{mg} / \mathrm{l})$ (Cronin et al. 2005), which is consistent with the effects on movement observed at $16 \mathrm{mg} / \mathrm{l}$ (Fig. 1).

Aldicarb exposure had a clear effect on life-history traits showing both classic dose response relationships, such as for broodsize, and more complex patterns such as those for life-span and length of the adult period. The difference between no effect concentrations on survival and growth/ reproduction indicated that sublethal endpoints are more sensitive to aldicarb than mortality by approximately a factor of two. Integration of all life-history effects in the Euler-Lotka equation showed that aldicarb had a minimal effect on population growth rate at low concentrations. Exposure above the lowest NEC in DEBtox $(1.99 \mathrm{mg} / \mathrm{l})$ should result in an effect on individual traits and therefore on population growth rate. However, this was not obvious from the projection of modelled population growth rate (Fig. 3d), which indicated that population growth rate only starts to deviate from controls above $6 \mathrm{mg} / \mathrm{l}$. The reasons for this discrepancy are likely to be complex and may relate to the complex nature of the survival response and also to slow toxicokinetics and dilution by growth (Table 1). Thus, even though an external concentration of around $4 \mathrm{mg} / \mathrm{l}$ will exceed the NEC for effects on maintenance costs, it will only do so late in life due to slow aldicarb uptake. The effects of low concentration exposure just above the NEC, thus, occur after reproduction ceases and so are not relevant for population growth rate. High concentration exposure $(16 \mathrm{mg} / \mathrm{l})$, in contrast, did reduce population growth rate by $38 \%$.

DEBtox fits using life-history data indicated that the most plausible energetic "mode of action" for aldicarb was 


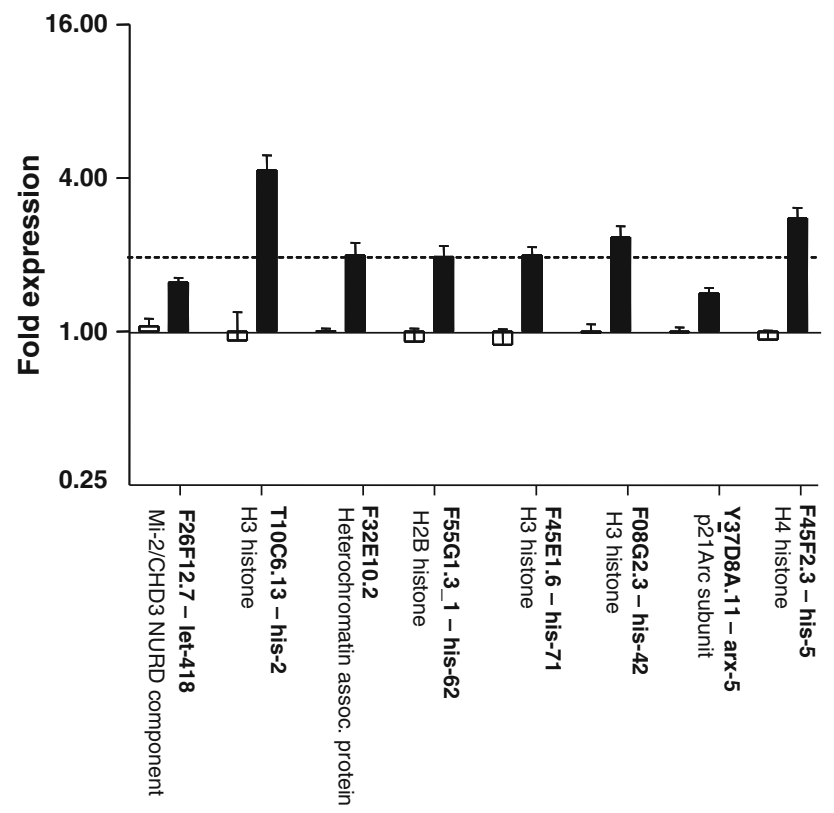

Fig. 4 Intensity levels of genes involved with chromatin assembly and DNA packaging which were upregulated in response to aldicarb, means are semilog plotted, error bars represent standard error of the mean, control showing as unshaded bars, aldicarb exposed nematode $(16 \mathrm{mg} / \mathrm{l})$ as shaded bars; dashed line of two-fold induction

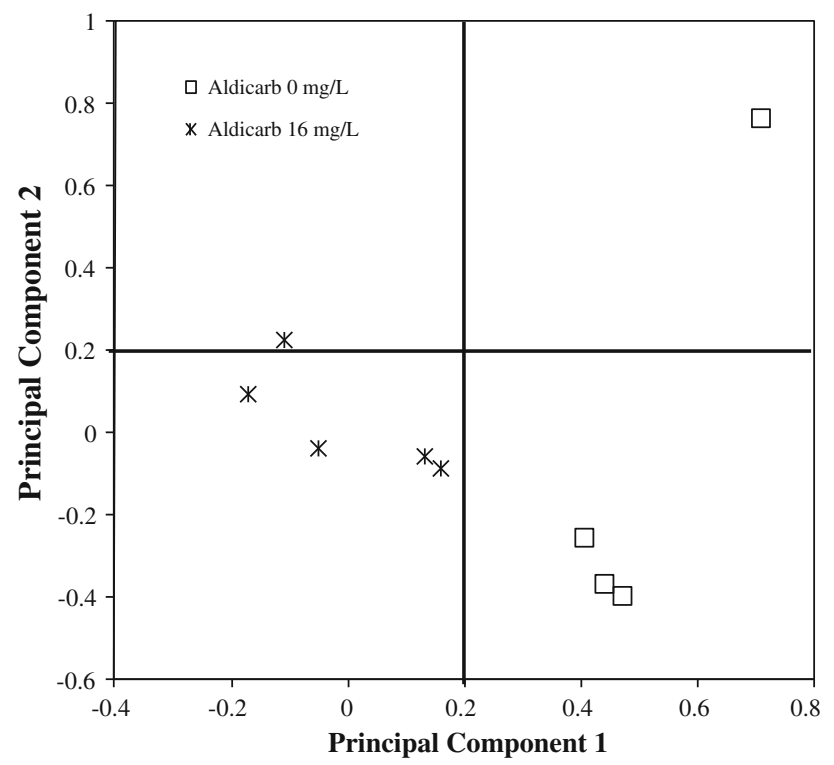

Fig. 5 Scores plot for PC1 and PC2 from a PCA of normalised whole genome microarray data for C. elegans exposed to control or $16 \mathrm{mg} / \mathrm{l}$ aldicarb

an increase in maintenance costs for somatic and reproductive tissue. This provides insight into the mechanisms of systemic aldicarb effects. To assess the detailed biological pathways that were involved in aldicarb toxicity we utilised a targeted whole genome microarray analysis of gene expression change following high level aldicarb exposure.
This analysis only involved gene expression analysis for worms exposed to the highest aldicarb treatment $(16 \mathrm{mg} / \mathrm{l})$. While this restricted assessment could not identify gene expression changes associated with all physiological effects of aldicarb (e.g. life-span extension at lower exposure levels), it did support a mechanistic assessment of the major toxicological effects of the pesticide for $C$. elegans.

A set of linked biochemical pathways have been suggested to be involved in maintaining tissues through detoxification and protection against cellular injury (Korsloot et al. 2004). These include metabolising enzymes, binding proteins, protein chaperones, signalling pathways and antioxidant defence mechanisms. The transcriptomic analysis confirmed a role for a selection of these pathways in nematode responses to aldicarb. For example, the pathway analysis highlighted genes involved in xenobiotic transformation to be differentially expressed. This is consistent with previous work that has identified that aldicarb is metabolised by nematodes and that the toxic sulphoxide metabolite is the primary metabolised form (Batterby et al. 1977). Up-regulation of such protective pathways provides a link between observed transcriptional remodelling following aldicarb exposure and the maintenance effects suggested by DEBtox modelling.

As well as highlighting the role of the biotransformation system in the toxicity of aldicarb, results from the whole genome microarray provided further insights into the mechanisms that underlie the observed aldicarb toxicity that go beyond the physiological level analysis possible through DEBtox modelling. Among pathways highlighted, one group was associated with DNA structure. These included chromatin assembly/disassembly and DNA packaging, including histones 2, 3 and 4 (Fig. 4). These changes each suggest that aldicarb can affect DNA structure either through genotoxicity (Cid and Matos 1984, 1987) or through effects of rates of DNA replication during germ cell production. While the results here suggest an interaction of aldicarb with DNA, further mechanistic studies utilising knock-out lines for genes associated with maintaining chromosomal integrity and DNA structure will be needed to further investigate this link.

The overrepresentation of pathways associated with protein metabolism and ubiquitination found by microarray also indicates that aldicarb has an effect on protein trafficking, tagging and turnover. Such changes may arise through damage induced by direct interaction of the chemical with proteins and/or through secondary ROS production and associated affects on macromolecule integrity. The reduction in the life-span in nematodes exposed to $16 \mathrm{mg} / \mathrm{l}$ (the concentration used for the microarray experiment) and effects on growth and reproduction provide further indications that the identified changes in protein turnover are associated with an increased likelihood 
of early mortality and reduced biomass and egg production that ultimately affects population growth rate.

While DEBtox analysis identified effects on resource allocation through maintenance costs, it was notable that pathways directly involved in energy metabolism, such as electron transport or ATP turnover were not highlighted. The statistically significant gene list did, however, contain a number of genes associated with energy acquisition through feeding (Supplementary Table 1). These include let-75 which is expressed exclusively in pharyngeal muscles and required for pharyngeal muscle contraction (Ardizzi and Epstein 1987); (Avery 1993) and for which repression could indicate reduced pharyngeal pumping and so feeding rate. Gene $n h x-2, \mathrm{a} \mathrm{Na}^{+} / \mathrm{H}^{+}$exchanger which has been shown to be required for normal growth (Kamath et al. 2003; Nehrke 2003) was also down-regulated. RNA interference of $n h x-2$ results in a reduction in body size, brood size, pharyngeal pumping rate, loss of fat stores and a $40 \%$ increase in post-reproductive lifespan (Nehrke 2003): traits that are consistent with those induced by high concentration aldicarb exposure. This suggests that as well as maintenance effects, resource acquisition may also be modulated by exposure to aldicarb.

A major metabolic pathway also highlighted in the analysis was fatty acid metabolism (Supplementary Fig. 2). Differential regulation within this pathway could suggest that overall metabolism is increased due to increased energy requirement. This, however, is not consistent with the observed down-regulation of genes involved in the feeding process or the absence of direct energy metabolism pathways from the overrepresented pathway list. An alternative explanation for the changes in fatty acid synthesis may be the association with changes in macromolecule metabolism and in particular in protein and amino acid turnover. Following amino acid deamination during catabolism, remaining carbon skeletons can be used either for direct energy synthesis via gluconeogenesis or can be stored via the fatty acid synthesis pathways. Thus, an effect on fatty acid synthesis is consistent with effects on protein metabolism as indicated within the GO enrichment analysis.

Based on its known mode of action, aldicarb is generally considered a specifically acting pesticide that targets inhibition of the acetylcholinesterase enzyme at the synaptic junction. While neurotoxicity remains as the most likely main mode of action, the current study has shown that aldicarb produces substantial transcriptional remodelling. This suggest that in addition to neurotoxicity, xenobiotic metabolism via cytochrome P450's, as well as pathways associated with chromatin assembly, protein turnover, fatty acid metabolism and possibly feeding behaviour are all involved in $C$. elegans responses to aldicarb. These observations are largely consistent with an extended system level effect of this chemical. However, while pathway analysis such as that conducted here can provide initial indications of possible effects, validation studies for individual genes are required to confirm the role of individual pathways. Such studies can include detailed gene-by-gene investigation of expression changes, or the utilisation of functional genetic resources, such as mutant strains, to verify the nature of phenotypic responses to aldicarb exposure.

Within ecotoxicogenomics, the linking of transcriptomic changes to the responses seen in life history of the individuals will be one of the major future challenges. In this context, combining individual-level models such as DEB with transcriptional analyses provides a more holistic assessment of both chemical mechanisms of action and the demographic changes that result from toxicity. With an increasing demand for more science-based risk assessment and the need to assess the risks of chemicals without increasing the number of vertebrate animals involved in testing programs, this combined demographic/mechanistic approach can provide initial information on mode(s) of action and relevant biomarkers that can reliably link exposure to ecologically relevant toxic effects.

Acknowledgments Many thanks to S. Hughes for performing the movement assays and to J. Chaseley, and V. Workman for array printing. Jodie Wren was in receipt of a UK Natural Environment Research Council (NERC) PhD studentship (NER/S/A/2002/11044) with additional stipend from AstraZeneca.

Open Access This article is distributed under the terms of the Creative Commons Attribution Noncommercial License which permits any noncommercial use, distribution, and reproduction in any medium, provided the original author(s) and source are credited.

\section{References}

Alda Alvarez OA, Jager T, Kooijman SALM, Kammenga JE (2005) Responses to stress of Caenorhabditis elegans populations with different reproductive strategies. Funct Ecol 19:656-664

Alda Alvarez OA, Jager T, Redondo EM, Kammenga JE (2006) Physiological modes of action of toxic chemicals in the nematode Acrobeloides nanus. Environ Toxicol Chem 25: 3230-3237

Ardizzi JP, Epstein HF (1987) Immunochemical localization of myosin heavy-chain isoforms and paramyosin in developmentally and structurally diverse muscle-cell types of the nematode Caenorhabditis elegans. J Cell Biol 105:2763-2770

Avery L (1993) The genetics of feeding in Caenorhabditis elegans. Genetics 133:897-917

Batterby S, Patourel GNJ, Wright DJ (1977) Accumulation and metabolism of aldicarb by the free-living nematodes Aphelenchus avenae and Panagrellus redivivus. Ann Appl Biol 86:69-76

Benjamini Y, Hochberg Y (1995) Controlling the false discovery rate-a practical and powerful approach to multiple testing. J Roy Stat Soc B 57:289-300

Brenner S (1974) The genetics of Caenorhabditis elegans. Genetics 77:71-94 
Bundy JG, Sidhu JK, Rana F, Spurgeon DJ, Svendsen C, Wren JF, Stürzenbaum SR, Morgan AJ, Kille P (2008) Systems toxicology' approach identifies coordinated metabolic responses to copper in a terrestrial non-model invertebrate, the earthworm Lumbricus rubellus. BMC Biol 6:1-25

Calow P, Sibly RM, Forbes V (1997) Risk assessment on the basis of simplified life-history scenarios. Environ Toxicol Chem 16: 1983-1989

Chomczynski P, Sacchi N (1987) Single step method of RNA isolation by acid guanidinium thiocyanate phenol chloroform extraction. Anal Biochem 162:156-159

Cid MG, Matos E (1984) Induction of sister-chromatid exchanges in cultured human-lymphocytes by aldicarb, a carbamate pesticide. Mutat Res 138:175-179

Cid MG, Matos E (1987) Chromosomal-aberrations in cultured human-lymphocytes treated with aldicarb, a carbamate pesticide. Mutat Res 191:99-103

Connon R, Hooper HL, Sibly RM, Lim FL, Heckmann LH, Moore DJ, Watanabe H, Soetaert A, Cook K, Maund SJ, Hutchinson TH, Moggs J, De Coen W, Iguchi T, Callaghan A (2008) Linking molecular and population stress responses in Daphnia magna exposed to cadmium. Environ Sci Technol 42:2181-2188

Cremlyn RJ (1991) Agrochemicals: preparation and mode of action. Wiley, Chichester, England

Cronin CJ, Mendel JE, Mukhtar S, Kim YM, Stirbl RC, Bruck J, Sternberg PW (2005) An automated system for measuring parameters of nematode sinusoidal movement. BMC Genetics 6 . doi:10.1186/1471-2156-6-5

Heckmann LH, Connon R, Hutchinson TH, Maund SJ, Sibly RM, Callaghan A (2006) Expression of target and reference genes in Daphnia magna exposed to ibuprofen. BMC Genomics 7:175

Howard PH (1991) Pesticides. In: Handbook of environmental fate and exposure data for organic chemicals. Lewis Publishers, Chelsea, MI, pp 3-15

Jager T, Crommentuijn T, VanGestel CAM, Kooijman SALM (2004) Simultaneous modeling of multiple end points in life-cycle toxicity tests. Environ Sci Technol 38:2894-2900

Jager T, Alda Alvarez OA, Kammenga JE, Kooijman SALM (2005) Modelling nematode life cycles using dynamic energy budgets. Funct Ecol 19:136-144

Jager T, Heugens EHW, Kooijman SALM (2006) Making sense of ecotoxicological test results: towards application of processbased models. Ecotoxicology 15:305-314

Kamath RS, Fraser AG, Dong Y, Poulin G, Durbin R, Gotta M, Kanapin A, Le Bot N, Moreno S, Sohrmann M, Welchman DP, Zipperlen P, Ahringer J (2003) Systematic functional analysis of the Caenorhabditis elegans genome using RNAi. Nature 421: 231-237

Kammenga JE, Busschers M, VanStraalen NM, Jepson PC, Bakker J (1996) Stress induced fitness reduction is not determined by the most sensitive life-cycle trait. Funct Ecol 10:106-111
Kooijman S (2001) Quantitative aspects of metabolic organization: a discussion of concepts. Phil Trans Roy Soc B 356:331-349

Kooijman S, Bedaux JJM (1996) Analysis of toxicity tests on Daphnia survival and reproduction. Water Res 30:1711-1723

Korsloot A, Van Gestel CAM, Van Straalen NM (2004) Environmental stress and cellular response in arthropods. CRC Press, London

Nehrke K (2003) A reduction in intestinal cell pH(i) due to loss of the Caenorhabditis elegans $\mathrm{Na}+\mathrm{H}+$ exchanger NHX-2 increases life span. J Biol Chem 278:44657-44666. doi:10.1074/jbc. M307351200

Opperman CH, Chang S (1991) Effects of aldicarb and fenamiphos on acetylcholinesterase and motility of Caenorhabditis elegans. J Nematol 23:20-27

Opperman CH, Chang S (1992) Nematode acetylcholinesterasesmolecular-forms and their potential role in nematode behavior. Parasitol Today 8:406-411

Owen J, Hedley BA, Svendsen C, Wren J, Jonker MJ, Hankard PK, Lister LJ, Stürzenbaum SR, Morgan AJ, Spurgeon DJ, Kille P, Blaxter ML (2008) Transcriptome profiling of developmental and xenobiotic responses in a keystone soil animal, the oligochaete annelid Lumbricus rubellus. BMC Genomics 6:266

Smith MM, Levitan DJ (2004) The Caenorhabditis elegans homolog of the putative prostate cancer susceptibility gene ELAC2, hoe-1, plays a role in germline proliferation. Develp Biol 266: 151-160. doi:10.1016/j.ydbio.2003.10.016

Soetaert A, van der Ven K, Moens LN, Vandenbrouck T, van Remortel P, De Coen WM (2007) Daphnia magna and ecotoxicogenomics: gene expression profiles of the anti-ecdysteroidal fungicide fenarimol using energy-, molting- and life stage-related cDNA libraries. Chemosphere 67:60-71

Svendsen C, Owen J, Kille P, Wren J, Jonker MJ, Headley BA, Morgan AJ, Blaxter M, Sturzenbaum SR, Hankard PK, Lister LJ, Spurgeon DJ (2008) Comparative transcriptomic responses to chronic cadmium, fluoranthene, and atrazine exposure in Lumbricus rubellus. Environ Sci Technol 42:4208-4214. doi:10.1021/ es702745d

Swain S, Wren J, Stürzenbaum SR, Kille P, Jager T, Jonker MJ, Hankard PK, Svendsen C, Chaseley J, Hedley BA, Blaxter M, Spurgeon DJ (2010) Linking toxicants mechanism of action and physiological mode of action in Caenorhabditis elegans. BMC Syst Biol 4. doi:10.1186/1752-0509-1184-1132

Walker CH (2008) Organic pollutants: an ecotoxicological perspective, Second edn. CRC Press, London, UK

Williams TD, Gensberg K, Minchin SD, Chipman JK (2003) A DNA expression array to detect toxic stress response in European flounder (Platichthys flesus). Aqua Toxicol 65:141-157 